\title{
Craig on McTaggart's Paradox and the problem of temporary intrinsics
}

\section{NATHAN OAKLANDER}

In his recent paper, William Lane Craig (1998) purports to establish the following four theses: (1) McTaggart's Paradox is a peculiar instance of the Problem of Temporary Intrinsics, i.e., the problem of change. ${ }^{1}(2)$ If one adopts a hybrid A-B theory which countenances both B-relations and nonrelational A-properties, then McTaggart's Paradox is unavoidable. (3) On the other hand, if one adopts a pure A-theory of time, i.e., the ontology of presentism, then the problem of temporary intrinsics and McTaggart's Paradox are adroitly dissolved. He concludes, therefore, that (4) 'the debate over McTaggart's Paradox needs to be re-focused on the tenability of the metaphysic of presentism' (126). Although I will have something to say about each of Craig's theses, I shall concentrate on the third, and argue that Craig's presentist ontology does not avoid the problems for which it was introduced. First some preliminaries.

The problem of ordinary change may be stated succinctly as follows: How can one and the same thing have incompatible intrinsic (that is, nonrelational) non-temporal properties such as being straight and being bent? The problem of temporal change (or temporal becoming) may be stated analogously: How can one and the same event have incompatible intrinsic temporal properties, such as being future, being present and being past? Although both questions are instances of the general problem: How can one and the same entity have incompatible properties? there is an important connection between them that their similarity masks, namely, temporal change is claimed by (some) tensers to explain ordinary change. Thus, for (some) tensers, a persisting thing $\mathrm{O}$ changing from straight to bent is explained by claiming that the events, O's being straight and O's being bent, each change from being future to being present to being past.

According to McTaggart, however, this explanation of ordinary change (or temporary intrinsics) involves a vicious circle since precisely the same incompatible properties problem that arose with regard things changing their non-temporal properties rearises with regard events changing their

${ }^{1}$ Craig claims that that the connection between McTaggart's paradox and the problem of identity and change 'has gone unnoticed in the philosophical literature' but he is mistaken since I raised it Oaklander (1984). Indeed, my extensive critique of numerous versions of the A-theory, including Prior's version of presentism, was based on the thesis that they all failed to avoid McTaggart's paradox since in one form or another they all gave rise to problem of change. 
temporal properties. And clearly, the vicious circularity will only turn into a vicious infinite regress if we introduce absolute moments, which remain the same through a temporal change of A-properties.

Although Craig does not present McTaggart's Paradox in the way I do I doubt he would disagree with it since he readily admits that if pastness and futurity are non-relational properties then tensers are in 'deep trouble' (126). On the other hand, according to Craig, presentism or a pure Atheory easily avoids both the problem of temporary intrinsics and McTaggart's Paradox. What, then, is the presentist solution to the problem of change? According to presentism, only the present exists. Thus, it is not the case that, say, $\mathrm{O}$ is bent and $\mathrm{O}$ is straight. Rather, as Craig puts it, $\mathrm{O}$ was bent at $t$, and $\mathrm{O} i s$ straight at $t^{*}$. Of course, whether this gambit avoids tenseless facts or is anything more than a verbal solution to a metaphysical problem depends on how Craig interprets time and tense. Before turning to those issues, however, consider his response to the problem of temporal change and McTaggart's paradox.

Craig maintains that

Applying this [the presentist] solution to the case of McTaggart's Paradox, we realize that the A-theorist cannot understand grammatical ascriptions of pastness and futurity to events in terms of the literal inherence of properties of pastness and futurity in events. For on a presentist ontology such items do not exist and so possess no properties. Such ascriptions must be parsed as asserting that the item in question was or will be F. Only ascriptions of presentness may be taken literally as the possession of an A-determination by some temporal item. The presentist thus adroitly avoids McTaggart's paradox because the only intrinsic tensed properties there are are presenttensed and therefore compatible (1998: 125-26, emphasis added).

The question I want to consider is simply this: If only ascriptions of presentness may be taken literally as the possession of an A-determination by some temporal item, then how are we to interpret ascriptions 'asserting that the item in question was or will be F'? In other words, what do the tenses 'was' and 'will be' represent?

The same question arises in Craig's response to David Lewis's criticism that on a presentist ontology persons have no past or future for he says that '[B]ut surely on presentism I have a past in the sense that I existed at and lived through times which once were present, and I have a future in that I shall exist and live through time which will be present' (1998: 127; emphasis added). However, Craig's reply cannot possibly stand on its own without an account of the ontological correlates of 'once were [i.e. was] present' and 'will be present' since if one countenances A-properties at all, 
such phrases imply the full range of A-properties and not only presentness, but pastness and futurity as well. What, then, is the Craig's metaphysics of presentism?

Craig is rather ambiguous on this point. He claims that McTaggart's Paradox constitutes a refutation of hybrid A-B theorists, which couples a B-theoretic ontology with objective non-relational A-properties, 'whereas it is in fact ineffectual against pure A-theorists like Broad, Prior, Christensen, Levison, and others' (126), but his account differs from Prior and others in several crucial respects. $^{2}$

For example, Prior, Levison and Christensen, reject an ontology that includes events, they reject the property of presentness that events acquire and shed, and most importantly, they reject the notion that there is a genuine change that an event, or anything else, undergoes as it becomes present and recedes into the past. There are only individual things and the present tensed facts that such individuals or substances enter into. As Prior puts it,

What I am suggesting is that what looks like talk about events is really at bottom talk about things, and that what looks like talk about changes in events is really just slightly more complicated talk about changes in things. ... The flow of time, we would then say, is merely metaphorical, not only because what is meant by it isn't a genuine movement, but further because what is meant by it isn't a genuine change .... (Prior 1968: 10-11; emphasis added.)

For Prior, McTaggart's Paradox does not arise because temporal becoming is not a species of change at all, and that is so because the subject of such changes (events or moments of time) and the monadic temporal Aproperties that such events are supposed to acquire and shed, do not exist. Since Craig countenances events or moments and the tensed property of presentness, Craig is not a pure A-theorist in the sense in which Prior and his followers are. Thus we must ask, once again, what then is Craig's account of presentism? Unless we are told, we cannot tell. Unfortunately, in the main body of his text Craig does not say, but in a footnote he does.

Craig's own explication of presentism begins with an appeal to the serious actualist's conception of possible worlds as states of affairs which exist as abstract objects but which are not instantiated. He then claims that

2 I should add that Craig's argument against the hybrid A-B theory does not consider Quentin Smith's theory since it fails to consider Smith's (1994) view that the infinite regress of tensed predication does not involve an appeal to moments (but rather to tensed exemplifications) and is not vicious. Moreover, and contrary to what Craig says, Smith would claim that a version of the second solution can resolve McTaggart's paradox since a momentary event can have temporal properties at times at which it does not exist. For an extended critique of Smith's response to McTaggart see Oaklander (1996). 
we can characterize presentism by allowing tensed states of affairs to be constituents of possible worlds. A tensed possible world is then a maximal possible state of affairs at some time $t$. Tensed possible worlds which did, do or will obtain are tensed actual worlds. The tensed actual world at $t$ will be the tensed actual world which obtains when $t$ 's being present obtains, or when $t$ is present. ... The tensed actual world $v$ is the maximal state of affairs that obtains (present tense). Were some other tensed possible world actual, then $v$ would not obtain, but it would still exist as a tensed possible state of affairs (1998: 126).

The appeal to tensed possible worlds which $d i d$, do, or will obtain can hardly provide a metaphysical explanation of what the tenses stand for in propositions reflecting ordinary and temporal change. Furthermore, the appeal to tensed possible worlds that change from existing to obtaining as they become present, that is, as presentness moves along the series of possible worlds, reintroduces the myth of passage that Craig found problematic. For his presentist ontology seems to entail a series of tensed possible worlds each existing (tenselessly) at the time they do, composed of the states of affairs they have, and changing with respect to actuality. How, then, can one and the same possible world (which exists whether or not it is present) have the incompatible properties of not obtaining and obtaining, or of not being actual and being actual?

If Craig replies that there is really no issue or contradiction to begin with since 'It will be the case that a possible world $v$ obtains' or 'It was the case that a possible world $v$ obtains,' but it is never the case that $v$ both obtains and does not obtain, then he is arguing in a vicious circle since the appeal to possible worlds was introduced to explicate the past and future tenses.

The problem with Craig's version of presentism can be stated in the form of a vicious infinite regress. Craig asserts that 'A tensed actual world at $t$, is the world which obtains when $t$ 's being present obtains... (p. 126), but when does t's being present obtain? Judging from his comments it appears that $t$ 's being present obtains before $t^{*}$ 's being present obtains (for any later $\left.t^{*}\right)$, since Craig maintains that

The tensed history of any possible world W will be all the tensed possible worlds constituted by the states of affairs entailed by W and each successive t's being present in W (1998: 126; emphasis added).

Thus, to explain when possible worlds obtain he appeals to succession, but since the appeal to succession implies the reality of B-relations, Craig's presentist ontology is not a pure A-theory, but a hybrid A-B theory which is, by his own lights, susceptible to McTaggart's paradox. In other words, the appeal to succession posits possible worlds existing at different times 
in a B-series and as presentness moves along each possible world takes its place in the spotlight of actuality and then falls out of it. This is the moving present theory of time that the metaphysic of presentism sought to avoid. I conclude, therefore, that if, as Craig says, 'hybrid A-B theorists, like McCall, Schlesinger, and Smith are, it seems, in deep trouble' (p. 127), then the same may be said of Craig's version of presentism as well.

\section{University of Michigan-Flint \\ Flint, MI 48502, USA lno@umich.edu}

\section{References}

Craig, W. L. 1998. McTaggart's Paradox and the problem of temporary intrinsics. Analysis 58: 122-27.

Prior, A. N. 1968. Changes in events and changes in things. In Time and Tense. Oxford: Clarendon Press.

Oaklander, L. N. 1984. Temporal Relations and Temporal Becoming: A Defense of a Russellian Theory of Time. Lantham MD. University Press of America.

Oaklander, L. N. 1996. McTaggart's Paradox and Smith's tensed theory of time. Synthese 107: 205-21

Smith, Q. 1994. McTaggart's paradox and the infinite regress of temporal attributions. In The New Theory of Time, eds. L. N. Oaklander and Q. Smith, 195-201. New Haven and London: Yale University Press. 